Revista Energia na Agricultura

ISSN 1808-8759

\title{
AVALIAÇÃO DO DESEMPENHO DAS MÁQUINAS AGRÍCOLAS NA IMPLANTAÇÃO DA CULTURA DO GIRASSOL ${ }^{1}$ JAIRO COSTA FERNANDES ${ }^{2} \&$ CARLOS ANTONIO GAMERO 3
}

RESUMO: O girassol é a quarta oleaginosa de reconhecida importância na produção de óleo e existem poucos estudos relacionados as operações agrícolas adotadas para esta cultura. Objetivou-se no presente trabalho estudar o desempenho das máquinas agrícolas no preparo convencional e reduzido na implantação da cultura do girassol. O experimento foi instalado na Fazenda Experimental do Lageado, pertencente à Faculdade de Ciências Agronômicas da UNESP - SP. Foi constituído de dois tipos de preparo (cultivo convencional-CC e cultivo reduzido-CR), com delineamento experimental em blocos casualizados e quatro repetições. O tratamento CC promoveu menor cobertura da superfície do solo protegida com resíduos, quando comparado ao tratamento $\mathrm{CR}$. O escarificador foi o equipamento de preparo que exigiu do trator maior força média de tração, potência média de tração e patinagem, conseqüentemente, promoveu menor velocidade média de trabalho. A capacidade de campo teórica e a área de solo mobilizada foram superiores no tratamento $\mathrm{CR}$, quando comparado ao tratamento $\mathrm{CC}$, promovendo assim menor consumo de combustível por hora de trabalho no tratamento CR..

Palavras-chave: Preparo reduzido, consumo de combustível, força de tração.

\footnotetext{
${ }^{1}$ Parte da tese de doutorado do primeiro autor intitulada: Avaliação do desempenho das máquinas agrícolas durante a implantação da cultura do girassol.

${ }^{2}$ Aluno do Curso de PG Energia na Agricultura - FCA/UNESP - Botucatu/SP - Brasil. costajf10@ hotmail.com

${ }^{3}$ Orientador e docente do Departamento de Engenharia Rural - FCA/UNESP - Botucatu/SP - Brasil.
} 


\section{PERFORMANCE ANALYSIS OF AGRICULTURAL MACHINES IN THE PLANTATION OF THE SUNFLOWER CROP}

SUMMARY: The sunflower oleaginous is the fourth of recognized importance in the oil production and few studies related to agricultural operations adopted for this crop. The objective of the present work was to study the performance of agricultural machines in the conventional tillage and reduced in the plantation of the sunflower crop. The experiment was installed at the Experimental Farm of Lageado, belonging to the Faculty of Agricultural Sciences of UNESP, located in Botucatu-SP. It consisted of two types of tillage (conventional tillage-CC and reduced tillage-CR), with experimental design in randomized blocks and four replications. The treatment CC promoted less coverage of the soil surface protected with waste when compared to CR treatment. The chisel plow was the tillage of equipment that required the tractor higher average traction force, average power traction and slippage, consequently, promoted lower average speed of work. The theoretical field capacity and area of land involved in the treatment CR were superior when compared to treatment CC, thereby lower consumption of fuel per hour worked was lower in CR treatment.

Keywords: Reduced tillage, fuel consumption, traction force.

\section{INTRODUÇÃO}

O Brasil é um país pouco expressivo na produção de girassol (grão), porém tanto a produção quanto a área colhida têm aumentado significativamente nos últimos cinco anos (SILVA, 2005). Visando o abastecimento interno, do complexo girassol, e com o advento do biodiesel, provavelmente esta cultura venha a crescer dentro do cenário nacional, nos próximos anos (CONAB, 2007).

Diversos tipos de preparo do solo são estudados com o fim de verificar a manutenção da fertilidade, o controle da erosão, a redução do custo das operações e proporcionar maior renda ao agricultor, com manejo sustentado do solo (RODRIGUES, 2001).

A escolha de um sistema de preparo é extremamente complexa, principalmente devido às variações dos tipos de solos, teores de água, coberturas vegetais sobre a superfície, culturas a serem implantadas, níveis tecnológicos, método de conservação, entre outras (FURLANI, 2000). No entanto, o preparo 
mais adequado deve ser decisivo para a escolha dos equipamentos a serem empregados e não o contrário (GAMERO et al., 1997).

Devido a essa crescente necessidade de tecnologias eficientes para a conservação dos recursos naturais e mais agudamente dos solos cultivados, tem-se buscado opções de sistemas de preparo do solo que provoquem menor desagregação e conservem maior quantidade de cobertura vegetal morta na superfície, a fim de reduzir o processo erosivo (FIGUEIREDO, 1991).

Segundo Gadanha Junior et al. (1991) o escarificador é um implemento que promove a desagregação do solo, sendo utilizado, também, para o rompimento de camadas compactadas. Além de permitir economia de combustível, a escarificação proporciona uma melhor conservação do solo e uma maior capacidade operacional da máquina agrícola, permitindo, assim, uma economia de tempo e dinheiro (MAIA, 1999).

Furlani (2000), estudando a combinação de três sistemas de preparo do solo (convencional, composto por uma aração e duas gradagens niveladoras; reduzido com escarificador; solo não preparado/semeadura direta) na cultura de inverno, utilizando o consórcio de aveia preta (Avena strigosa Shreb.) e o nabo forrageiro (Raphanus sativus L.) e na cultura de verão, utilizando o feijoeiro (Phaseolus vulgaris L.), observou que a cobertura do solo pelos restos das culturas de inverno, após a semeadura da cultura do feijoeiro, foi $76 \%$ para o sistema de semeadura direta, $37 \%$ e $8 \%$ para os preparos reduzido e convencional, respectivamente.

Salvador e Benez (1993) verificaram que, dentre as operações de preparo do solo, aquela realizada com arado de disco exigiu maior demanda de energia, seguida da grade pesada e escarificador, porém o escarificador apresentou tendência de menor consumo de combustível e demanda de potência por unidade de área mobilizada.

Levien (1999) verificou que o preparo convencional (arado de disco seguido de duas gradagens leves) resultou em maior demanda de potência e consumo de combustível nas operações de preparo do solo e semeadura do milho em comparação ao plantio direto, apresentando uma posição intermediária em relação à operação de escarificação.

Avaliando o desempenho operacional dos métodos de preparo de solo, Levien et al. (2003) observaram que a capacidade operacional no preparo reduzido do solo foi três vezes maior, bem como demandou $21 \%$ menos potência e $52 \%$ menos combustível, por área trabalhada, do que quando comparado com o preparo convencional.

Objetivou-se no presente trabalho estudar o desempenho das máquinas agrícolas no preparo convencional e reduzido na implantação da cultura do girassol. 


\section{MATERIAL E MÉTODOS}

O experimento foi instalado no ano agrícola de 2007, na Fazenda Experimental Lageado, pertencente à Faculdade de Ciências Agronômicas UNESP, localizada no município de Botucatu - SP. A localização geográfica está definida pelas coordenadas $22^{\circ} 49^{\prime}$ de latitude Sul e $48^{\circ} 25^{\prime}$ de longitude Oeste de Greenwich, unidade de mapeamento Lageado que ocupa $42 \%$ da fazenda, com altitude média de $770 \mathrm{~m}$ e declividade de $0,045 \mathrm{~m} \mathrm{~m}^{-1}$. A área experimental é conhecida como "área 54" situada ao lado da Rodovia Alcides Soares (Botucatu - Vitoriana) e vinha sendo cultivada no sistema de semeadura direta durante 11 anos, com rotação de soja e milho no verão, safrinha de milho e aveia ou triticale no inverno. O solo da área experimental foi classificado como Nitossolo Vermelho Distroférrico típico A moderado, textura argilosa e muito argiloso, relevo ondulado (NVdf), em conformidade com o Sistema Brasileiro de Classificação do Solo (EMBRAPA, 2006).

Os resultados dos atributos físicos do solo para caracterização da área experimental são apresentados na Tabela 1.

Tabela 1 - Atributos do solo para caracterização da área experimental, na camada de $0-20 \mathrm{~cm}$ de profundidade.

\begin{tabular}{lr}
\hline & Atributos do solo \\
\hline Areia Grossa $\left(\mathrm{g} \mathrm{kg}^{-1}\right)$ & Valor \\
Areia Fina $\left(\mathrm{g} \mathrm{kg}^{-1}\right)$ & 16,00 \\
Areia Total $\left(\mathrm{g} \mathrm{kg}^{-1}\right)$ & 86,75 \\
Silte $\left(\mathrm{g} \mathrm{kg}^{-1}\right)$ & 102,75 \\
Argila $\left(\mathrm{g} \mathrm{kg}^{-1}\right)$ & 279,50 \\
Densidade de partículas $\left(\mathrm{kg} \mathrm{dm}^{-3}\right)$ & 617,75 \\
Teor de água de máxima compactação $\left(\mathrm{g} \mathrm{kg}^{-1}\right)$ & 3,00 \\
\hline
\end{tabular}

O experimento foi constituído de dois tipos de preparo com quatro repetições, com delineamento experimental em blocos casualizados. Cada parcela teve $11,2 \mathrm{~m}$ de largura por $20 \mathrm{~m}$ de comprimento (16 linhas espaçadas $0,7 \mathrm{~m}$ ). Os blocos e as parcelas foram separados por carreadores de 8 e $10 \mathrm{~m}$ de comprimento entre eles, respectivamente. 
As parcelas foram constituídas pelos seguintes tipos de preparo do solo: Preparo do solo com escarificador de 7 hastes conjugado com rolo destorroador (CR); Preparo do solo com arado de disco seguido de grade leve (CC).

$\mathrm{Na}$ instalação do experimento foram utilizadas as seguintes máquinas agrícolas:

- Trator John Deere, tração 4x2 TDA, potência de 88,2 kW (121 cv), modelo 6600, utilizado para realização da gradagem, escarificação, semeadura do girassol e tracionamento do comboio durante a medição da força de tração na operação de aração;

- Trator Massey Ferguson, tração 4x2 TDA, potência de 63,5 kW (86 cv), modelo MF 283, utilizado para as operações de comboio durante a aração;

- Arado reversível, montado, de quatro discos com diâmetro de $762 \mathrm{~mm}$ (30"), espaçados em 610 $\mathrm{mm}$; ângulos horizontal e vertical de $48^{\circ}$ e $20^{\circ}$ respectivamente; largura de corte de $1.300 \mathrm{~mm}$ e massa de $810 \mathrm{~kg}$;

- Grade leve excêntrica, modelo GNL/32-784 de arrasto com 32 discos de 508 mm (20") de diâmetro cada, sendo os da seção dianteira de bordas recortados e os posteriores de bordas lisos, espaçados entre si em $170 \mathrm{~mm}$; ângulo de $34^{\circ}$ entre as seções e de $18^{\circ}$ de ataque dos discos; largura de corte 2.550 mm e massa de $758 \mathrm{~kg}$;

- Escarificador de arrasto, levante no sistema hidráulico; equipado com sete hastes protegidas com sistema de segurança por mola plana, espaçadas a $350 \mathrm{~mm}$, ponteiras de $60 \mathrm{~mm}$ de largura, $430 \mathrm{~mm}$ de comprimento, e ângulo de $24^{\circ}$ com a horizontal; conjugado com discos de corte flutuantes de $457 \mathrm{~mm}$ (18") inseridos à frente de cada haste; cilindro destorroador/nivelador na parte posterior, com largura de $2.800 \mathrm{~mm}$ e massa de $1.075 \mathrm{~kg}$.

As variáveis analisadas foram: cobertura na superfície do solo por resíduos vegetais, teor de água do solo no dia dos preparos, velocidade média, força média de tração, potência média de tração, patinagem do trator, capacidade de campo teórica, consumo operacional e horário de combustível, profundidade média de preparo e área de solo mobilizada.

Para a determinação da cobertura na superfície do solo por resíduos vegetais seguiu a metodologia descrita por Laflen et al. (1981).

Para determinação do teor de água no dia do preparo do solo, foi utilizado o método gravimétrico descrito pela EMBRAPA (1997).

$\mathrm{Na}$ determinação da velocidade média e patinagem das rodas motrizes do trator foram utilizados um cronômetro e duas balizas alinhadas no início e fim das parcelas experimentais.

Para determinação da força média de tração na barra foram utilizadas uma célula de carga, com capacidade de 100 kN, um berço e um sistema de aquisição de dados. 
Para determinação do consumo de combustível foram utilizados um fluxômetro, com precisão de $0,01 \mathrm{~mL}$ e um sistema de aquisição de dados.

Para o cálculo da profundidade média de preparo e área de solo mobilizada utilizou-se um perfilômetro de madeira com 40 hastes graduadas em centímetros, espaçadas a cada $5 \mathrm{~cm}$, instalado sobre marcadores de madeira que foi colocado transversalmente no início das parcelas. Os perfís foram determinados antes do preparo, após o uso do equipamento e depois da retirada do solo. No final das parcelas foram lidos os perfís mobilizados após o uso do arado e da grade leve.

Os resultados foram submetidos à análise de variância e logo após, utilizou-se o teste de Tukey a 5\% de probabilidade. A análise estatística foi realizada utilizando o programa de estatística "SISVAR" Sistema de Análise de Variância - da Universidade Federal de Lavras (FERREIRA, 2000).

\section{RESULTADOS E DISCUSSÃO}

Os resultados obtidos são apresentados na forma de Tabelas e quando ocorrer a ausência de letras entre os valores é indicação de que não houve significância pelo teste de $\mathrm{F}$ a $5 \%$ de probabilidade. As abreviações citadas em Tabelas e textos correspondem aos tipos de preparo: CR (Cultivo reduzido) e CC (Cultivo convencional).

Na Tabela 2 são apresentados os resultados da percentagem de cobertura na superfície do solo com resíduos vegetais da safra anterior e plantas daninhas presentes na área após os tipos de preparo do solo. Antes de qualquer interferência mecânica, havia na superfície do solo mais de $80 \%$ de cobertura vegetal, representando uma média de $6.268,07 \mathrm{~kg} \mathrm{ha}^{-1}$ de massa seca.

Tabela 2 - Cobertura na superfície do solo por resíduos vegetais da safra anterior e plantas daninhas presentes na área após os tipos de preparo do solo.

\begin{tabular}{cc}
\hline Tipos de preparo do solo & Cobertura na superfície do solo (\%) \\
\hline Semeadura direta & $92,17 \mathrm{a}$ \\
$\mathrm{CR}$ & $30,38 \mathrm{~b}$ \\
$\mathrm{CC}$ & $5,83 \mathrm{c}$ \\
\hline
\end{tabular}

$\overline{\mathrm{MS}}=13,07 ; \mathrm{CV}=10,74$. 
Comparando a cobertura na superfície do solo após os tipos de preparo do solo utilizados, verificou-se que o tratamento CC apresentou as menores percentagens de cobertura, mantendo, apenas, 5,83\% da superfície do solo protegida com resíduos. Isto é explicado pela mobilização e inversão das camadas superficiais do solo pelos órgãos ativos do arado e incorporação de grande parte dos resíduos vegetais que estavam presentes na superfície, o que concorda com os resultados obtidos por Siqueira (1999), quando comparou a operação de escarificação com o preparo do solo utilizando arado de disco e aiveca.

Levien e Gamero (2000) verificaram que o preparo convencional (arado de disco seguido de duas grades leves) promoveu, em média, redução de $85 \%$ na porcentagem de cobertura do solo com aveia preta.

O tratamento CR apresentou valores de cobertura (30,38\%) inferiores aos 38,3\% encontrados por Boller et al. (1997) e 37\% por Furlani et al. (2004). Mesmo assim, o tratamento CR, pode ser considerado como preparo conservacionista, por ter apresentado valores de cobertura vegetal no solo após a escarificação, acima de 30\%, conforme relatado por Magleby e Shertz (1988).

Os resultados dos valores médios obtidos para o teor de água no dia dos preparos do solo encontram-se na Tabela 3, em que pode-se observar que não houve significância pelo teste de $\mathrm{F}$ a $5 \%$ de probabilidade, para os sistemas de manejo e profundidades.

Tabela 3 - Teor de água do solo $\left(\mathrm{g} \mathrm{kg}^{-1}\right)$ no dia dos preparos do solo.

\begin{tabular}{|c|c|c|c|}
\hline \multirow{2}{*}{$\begin{array}{l}\text { Profundidade } \\
(\mathrm{mm})\end{array}$} & \multicolumn{3}{|c|}{ Sistemas de manejo } \\
\hline & $\mathrm{CR}$ & $\mathrm{CC}$ & Médias \\
\hline $0-100$ & 295,28 & 294,30 & 294,78 \\
\hline $100-200$ & 293,83 & 299,20 & 296,51 \\
\hline $200-300$ & 275,48 & 294,08 & 284,78 \\
\hline Médias & 288,19 & 295,86 & \\
\hline
\end{tabular}

Os valores encontrados para os teores de água estão dentro da faixa de friabilidade que é apropriada para o preparo do solo. No entanto, com relação ao teor de água de máxima compactação (Tabela 1) verificou-se que os valores são comprometedores à estrutura física do solo quando o preparo é realizado nestas condições. 
Independentemente do teor de água existente, o solo está sempre susceptível a compactação ocasionada, principalmente, pelo tráfego das máquinas. Assim, no momento do preparo do solo, não se deve considerar, somente, a faixa de friabilidade, mas também o teor de água de máxima compactação determinado no ensaio de proctor.

Os valores das variáveis velocidade média, força média de tração, potência média de tração, patinagem do trator e capacidade de campo teórica, encontram-se na Tabela 4. Verifica-se, nesta Tabela, que não foi possível aplicar um teste de média para comparar o desempenho dos equipamentos de preparo do solo, pois no tratamento CC, foram realizadas duas operações distintas.

Tabela 4 - Velocidade média, força média de tração, potência média de tração, patinagem do trator e capacidade de campo teórica para os diferentes tipos de preparo do solo.

\begin{tabular}{ccccccc}
\hline $\begin{array}{c}\text { Tipos de } \\
\text { preparo }\end{array}$ & $\begin{array}{c}\text { Equipamentos } \\
\text { de preparo }\end{array}$ & $\begin{array}{c}\text { Velocidade } \\
\text { média }\end{array}$ & $\begin{array}{c}\text { Força média } \\
\text { de tração }\end{array}$ & $\begin{array}{c}\text { Potência } \\
\text { média de } \\
\text { tração }\end{array}$ & $\begin{array}{c}\text { Patinagem } \\
\text { do trator }\end{array}$ & $\begin{array}{c}\text { Capacidade } \\
\text { de campo } \\
\text { teórica }\end{array}$ \\
\hline & & $\mathrm{km} \mathrm{h}^{-1}$ & $\mathrm{kN}$ & $\mathrm{kW}$ & $\%$ & $\mathrm{ha} \mathrm{h}^{-1}$ \\
\cline { 2 - 7 } & Arado de disco & 3,79 & 14,48 & 15,22 & 8,54 & 0,49 \\
$\mathrm{CC}$ & Grade leve & 5,01 & 9,50 & 13,22 & 5,61 & 1,28 \\
$\mathrm{CR}$ & Escarificador & 2,87 & 41,59 & 32,93 & 22,53 & 0,80 \\
\hline
\end{tabular}

$\mathrm{Na}$ Tabela 4, verifica-se que o escarificador foi o equipamento de preparo que exigiu do trator maior força média de tração $(41,59 \mathrm{kN})$, potência média de tração $(32,93 \mathrm{~kW})$ e patinagem $(22,53 \%)$ e, conseqüentemente, promoveu menor velocidade média de trabalho $\left(2,87 \mathrm{~km} \mathrm{~h}^{-1}\right)$.

A capacidade de campo teórica fornece o ritmo teórico de trabalho executado, não considerando a área mobilizada no solo pelo equipamento. Equipamentos que operam com profundidades de trabalho diferentes não devem ser comparados, neste caso, o arado de disco e o escarificador, apresentaram profundidades de preparo semelhantes (Tabela 5).

Mesmo apresentando menor velocidade de trabalho, a capacidade de campo teórica no tratamento $\mathrm{CR}\left(0,80 \mathrm{ha} \mathrm{h}^{-1}\right)$, foi superior àquela obtida para o arado de disco no tratamento $\mathrm{CC}\left(0,49 \mathrm{ha} \mathrm{h}^{-1}\right)$, devido ao fato do escarificador apresentar maior largura de trabalho (Tabela 4). 
Lopes et al. (2005), utilizando-se do mesmo trator, tipo de pneu e tracionando um escarificador de sete hastes a profundidade média de $30 \mathrm{~cm}$, encontraram potência inferior $(22,66 \mathrm{~kW})$, àquela apresentada neste estudo (32,93 kW), mesmo trabalhando a uma maior velocidade $\left(3,18 \mathrm{~km} \mathrm{~h}^{-1}\right)$.

Levien (1999), utilizando-se do mesmo trator, escarificador e tipo de solo, operando a profundidade média de 17,5 cm, encontrou valores inferiores para as variáveis: velocidade média $\left(2,62 \mathrm{~km} \mathrm{~h}^{-1}\right)$, força média de tração $(38,22 \mathrm{kN})$, potência média de tração $(27,78 \mathrm{~kW})$ e capacidade de campo teórica $(0,73$ ha $\left.\mathrm{h}^{-1}\right)$.

Verificou-se que o valor para a capacidade de campo teórica, na operação de escarificação, foi semelhante ao encontrado por Boller (1996) de $0,81 \mathrm{ha} \mathrm{h}^{-1}$ e inferior para velocidade de trabalho $(3,72 \mathrm{~km}$ $\left.h^{-1}\right)$.

Levien (1999), utilizando-se do mesmo trator e arado de quatro discos, encontrou para as variáveis: velocidade média $4,42 \mathrm{~km} \mathrm{~h}^{-1}$; força média de tração $18,60 \mathrm{kN}$; potência média de tração $22,78 \mathrm{~kW}$ e capacidade de campo teórica $0,69 \mathrm{ha} \mathrm{h}^{-1}$, valores estes superiores aos encontrados neste estudo, e confirmados por Boller (1996), para a velocidade média 4,98 $\mathrm{km} \mathrm{h}^{-1}$ e capacidade de campo teórica $0,58 \mathrm{ha} \mathrm{h}^{-1}$.

Com relação à operação de gradagem, os valores de velocidade média de $5,01 \mathrm{~km} \mathrm{~h}^{-1} \mathrm{e}$ capacidade de campo teórica de 1,28 ha $\mathrm{h}^{-1}$ (Tabela 4), foram menores que os valores encontrados por Levien (1999), que foi de $5,87 \mathrm{~km} \mathrm{~h}^{-1}$ e 1,35 ha h${ }^{-1}$, respectivamente. Já, para os valores de força média $(6,22 \mathrm{kN})$ e potência média de tração $(10,10 \mathrm{~kW})$, o autor obteve valor superior.

$\mathrm{Na}$ Tabela 5, são apresentados os dados do consumo operacional e horário de combustível, profundidade média de preparo e área de solo mobilizada. Analisando-se o consumo de combustível operacional, entre os sistemas de manejo, verifica-se que não ocorreram diferenças estatísticas, mesmo observando uma redução de $29,27 \%$ no tratamento CR, quando comparado ao tratamento CC.

O consumo de combustível operacional no tratamento CC $\left(30,75 \mathrm{~L} \mathrm{ha}^{-1}\right)$ foi semelhante ao obtido por Boller (1996) de 30,43 $\mathrm{L} \mathrm{ha}^{-1}$, porém inferior ao encontrado por Levien (1999) de 33,74 $\mathrm{L} \mathrm{ha}^{-1}$, e o consumo horário de combustível no tratamento $\mathrm{CC}\left(22,50 \mathrm{~L} \mathrm{~h}^{-1}\right)$, foi inferior ao encontrado por Boller (1996) de 28,5 $\mathrm{L} \mathrm{h}^{-1}$ e Levien (1999) de 29,50 $\mathrm{L} \mathrm{h}^{-1}$. 
Tabela 5 - Valores médios do consumo operacional e horário de combustível, profundidade média de preparo e área de solo mobilizada.

\begin{tabular}{ccccc}
\hline \multirow{2}{*}{ Tipos de preparo } & $\begin{array}{c}\text { Consumo ope- } \\
\text { racional }\end{array}$ & $\begin{array}{c}{ }^{2} \text { Consumo } \\
\text { horário }\end{array}$ & $\begin{array}{c}{ }^{3} \text { Profundidade } \\
\text { média de preparo }\end{array}$ & $\begin{array}{c}{ }^{4} \text { Área de solo } \\
\text { mobilizada }\end{array}$ \\
\cline { 2 - 5 } $\mathrm{CC}$ & 30,75 & $22,50 \mathrm{a}$ & 155 & $\mathrm{~cm}^{2}$ \\
$\mathrm{~L} \mathrm{ha}{ }^{-1}$ & $\mathrm{~L} \mathrm{~h}^{-1}$ & $\mathrm{~mm}$ & $2.020,75 \mathrm{~b}$ \\
$\mathrm{CR}$ & 21,75 & $17,00 \mathrm{~b}$ & 156 & $4.359,00 \mathrm{a}$ \\
\hline
\end{tabular}

${ }^{\mathrm{D}} \mathrm{DSS} \mathrm{p} /$ preparo do solo $=9,63 ; \mathrm{CV}(\%)=16,31$.

${ }^{2} \mathrm{DMS} \mathrm{p} /$ preparo do solo $=: 3,31 ; \mathrm{CV}(\%)=7,45$.

${ }^{3} \mathrm{DMS}$ p/ preparo do solo $=12,63 ; \mathrm{CV}(\%)=3,60$.

${ }^{4} \mathrm{DMS}$ p/ preparo do solo $=195,73 ; \mathrm{CV}(\%)=2,73$.

$\mathrm{Na}$ operação de cultivo reduzido (escarificador), obteve-se o menor consumo de combustível por hora de trabalho $\left(\mathrm{L} \mathrm{h}^{-1}\right)$, quando comparado com o cultivo convencional (aração seguida de gradagem), mesmo trabalhando a uma menor velocidade $\left(2,87 \mathrm{~km} \mathrm{~h}^{-1}\right)$. O consumo médio de combustível foi de 22,5 e 17,00 $\mathrm{L} \mathrm{h}^{-1}$, para os tratamentos CC e CR respectivamente, com uma economia média de 5,50 $\mathrm{L} \mathrm{h}^{-1}$, quando se utilizou o tratamento CR (Tabela 5).

O consumo horário médio durante a operação de escarificação $\left(17,00 \mathrm{~L} \mathrm{~h}^{-1}\right)$ foi superior ao encontrado por Furlani (2000) de 14,2 $\mathrm{L} \mathrm{h}^{-1}$ e Levien (1999) de 14,89 $\mathrm{L} \mathrm{h}^{-1}$, isso devido a velocidade, força e potência média de tração serem superior neste estudo.

Observando os valores de profundidade média de preparo, verifica-se que não houve significância pelo teste $\mathrm{F}$ a $5 \%$ de probabilidade entre os tratamentos CR e CC (Tabela 5).

Analisando a área de solo mobilizada, observou-se que o tratamento CC apresentou menor área $\left(2.020,75 \mathrm{~cm}^{2}\right)$, quando comparado ao tratamento $\mathrm{CR}\left(4.359,00 \mathrm{~cm}^{2}\right)$, devido à maior largura de trabalho do escarificador, pois as profundidades de trabalho dos equipamentos foram semelhantes (Tabela 5).

A área de solo mobilizada pelo arado foi inferior àquelas encontradas por Siqueira (1999) e Boller et al. (1997) que foram de $3.799,00 \mathrm{~cm}^{2}$ e $2.663,00 \mathrm{~cm}^{2}$, respectivamente. Para o escarificador, a área de solo mobilizada foi inferior àquelas encontradas por Siqueira (1999) e Levien (1999), que foi de 6.840,00 $\mathrm{cm}^{2}$ e 4.904,00 $\mathrm{cm}^{2}$, respectivamente e superior a encontrada por Boller et al. (1997) de 4.113,00 $\mathrm{cm}^{2}$. 


\section{CONCLUSÕES}

O tratamento CC promoveu menor cobertura da superfície do solo protegida com resíduos, quando comparado ao tratamento $\mathrm{CR}$.

O escarificador foi o equipamento de preparo que exigiu do trator maior força média de tração, potência média de tração e patinagem e, conseqüentemente, promoveu menor velocidade média de trabalho.

A capacidade de campo teórica e a área de solo mobilizada foram superiores no tratamento CR, quando comparado ao tratamento CC.

O consumo de combustível operacional não se diferiu estatisticamente entre os tipos de preparo. Já o consumo de combustível por hora de trabalho foi menor no tratamento $\mathrm{CR}$, quando comparado ao tratamento CC.

\section{REFERÊNCIAS}

BOLLER, W. Avaliação de diferentes sistemas de manejo do solo visando a implantação da cultura do feijão (Phaseolus vulgaris L.). 1996. 272 f. Tese (Doutorado em Agronomia/Energia na Agricultura)Faculdade de Ciências Agronômicas, Universidade Estadual Paulista, Botucatu, 1996.

BOLLER, W.; GAMERO, C. A.; PEREIRA, O. J. Avaliação de diferentes sistemas de preparo e de condições de cobertura do solo. Engenharia Agrícola, Jaboticabal, v. 17, n. 2, p. 52-63, 1997.

\section{COMPANHIA NACIONAL DE ABASTECIMENTO. Safras. Disponível em:}

$<$ http://www.conabgov.br/conabweb/download/safra/GirassolSerie Hist.xls $>$. Acesso em: 18 dez. 2007.

EMBRAPA. Sistema brasileiro de classificação de solos. Brasília, DF, 2006. 306 p. 
EMBRAPA. Manual de métodos de análises do solo. 2. ed. Rio de Janeiro, 1997. 212 p.

FERREIRA, D. F. Análises estatísticas por meio do Sisvar para Windows versão 4.0. In...45 REUNIÃO ANUAL DA REGIÃO BRASILEIRA DA SOCIEDADE INTERNACIONAL DE BIOMETRIA. UFSCar, São Carlos, SP, Julho de 2000. p.255-258.

FIGUEIREDO, P. R. A de. Otimização do desempenho de uma máquina de manejo mínimo de solo. 1991. 98 f. Dissertação (Mestrado em Engenharia Agrícola)-Faculdade de Engenharia Agrícola, Universidade Estadual de Campinas, Campinas, 1991.

FURLANI, C. E. A. Efeito do manejo do solo e do manejo da cobertura de inverno na cultura do feijoeiro (Phaseolus vulgaris L.). 2000. 218 f. Tese (Doutorado em Agronomia/Energia na Agricultura)Faculdade de Ciências Agronômicas, Universidade Estadual Paulista, Botucatu, 2000.

FURLANI, C. E. A et al. Desempenho operacional de uma semeadora-adubadora de precisão, em função do manejo do solo e do manejo da cobertura de inverno. Engenharia Agrícola, Jaboticabal, v. 24, n. 2, p. 388-395, 2004.

GADANHA JUNIOR, C. D. et al. Máquinas e implementos agrícolas do Brasil. São Paulo: Instituto de Pesquisas Tecnológicas do Estado de São Paulo, 1991. 468 p.

GAMERO, C. A. et al. Decomposição da aveia preta (Avena strigosa Schreb) manejada com rolo-faca e triturador de palhas. In: CONGRESSO BRASILEIRO DE ENGENHARIA AGRÍCOLA, 26., 1997, Campina Grande. Anais... Campina Grande: Universidade Federal da Paraíba, 1997. CD ROM. 
LAFLEN, J. M.; AMENIYA, A.; HINTZ, E. A. Measuring crop residue cover. Journal of Soil and Water Conservation, Ankeny, v. 36, n. 6, p. 341-343, 1981.

LEVIEN, R. Condições de cobertura e método de manejo do solo para a implantação da cultura do milho (Zea mays L.). 1999. 305 f. Tese (Doutorando em Agronomia/Energia na Agricultura)-Faculdade de Ciências Agronômicas, Universidade Estadual Paulista, Botucatu, 1999.

LEVIEN, R.; GAMERO, C. A. Semeadura de milho em diferentes manejos e condições de cobertura do solo: primeiro ano de implantação. Energia na Agricultura, Botucatu, v. 15, n. 4, p. 82-97, 2000.

LEVIEN, R.; GAMERO, C. A.; FURLANI, E. A. Manejo convencional e reduzido em solo argiloso em diferentes condições de cobertura de inverno. Engenharia Agrícola, Jaboticabal, SP, v. 23, n. 2, p. $277-$ 289, 2003.

LOPES, A. et al. Desempenho de um trator em função do tipo de pneu da lastragem e da velocidade de trabalho. Ciência Rural, Santa Maria, v. 35, n. 2, p. 366-370, 2005.

MAIA, J. C. de S. Determinação de esquemas de amostragem para avaliação de propriedades físicas do solo sob diferentes sistemas de manejo. 1999. 158 f. Tese (Doutorado em Engenharia Agrícola) Faculdade de Engenharia Agrícola, Universidade Estadual de Campinas, Campinas, 1999.

MAGLEBY, R. S.; SCHERTZ, D. L. Conservation tillage chalks up steady gains. Agricultural Engineering, St. Joseph, v. 67, n. 1, p. 6-14, 1988. 
RODRIGUES, R. A. F. Efeitos de tipos de manejos nos seus atributos físicos do solo e nas características fenológicas e produtividades do arroz de terras altas irrigado por aspersão. 2001. 75 f. Tese (Livre Docência)-Faculdade de Engenharia, Universidade Estadual Paulista, Ilha Solteira, 2001.

SALVADOR, N.; BENEZ, S. H. Manejo periódico do solo II: consumo energético e desagregação do solo. In: CONGRESSO BRASILEIRO DE ENGENHARIA AGRÍCOLA, 22., 1993, Ilhéus: Anais... Ilhéus: Sociedade Brasileira de Engenharia Agrícola, 1993. p. 1722-1731.

SIQUEIRA, R. Sistemas de preparo em diferentes tipos de coberturas vegetais do solo, 1999. $191 \mathrm{f}$. Tese (Doutorado em Agronomia/Energia na Agricultura)-Faculdade de Ciências Agronômicas, Universidade Estadual Paulista, Botucatu, 1999.

SILVA, M. de L. O. Aplicações de lâminas de água e doses de boro na cultura do girassol. 2005. 128

f. Tese (Doutorado em Irrigação e Drenagem)-Universidade Federal de Lavras, Lavras, 2005. 